\title{
INHERITED INTERPOPULATION DIFFERENCES IN SIZE AT FIRST REPRODUCTION IN THREESPINE STICKLEBACK, GASTEROSTEUS ACULEATUS L.
}

\author{
J. D. MCPHAIL \\ Department of Zoology and Institute of Animal Resource Ecology, University of British Columbia, \\ 2076 Wesbrook Place, Vancouver V6T 1W5, Canada
}

Received 4.viii.76

\begin{abstract}
SUMmary
Minimum female size at first reproduction is examined in 25 lacustrine populations of sticklebacks ( $G$. aculeatus). Field and laboratory data indicate that interpopulation differences in minimum size at first reproduction are inherited and probably represent local adaptations. Some possible selective factors are examined and predation by trout is suggested as a mechanism selecting for extremes (either small or large) sizes at first reproduction.
\end{abstract}

\section{INTRODUCTION}

MAYR (1963) points out that size is perhaps the most universally variable character in species with extensive geographic ranges. Although this variation is most apparent in birds and mammals, the generalisation also is valid for fishes. Certainly, interpopulation differences in growth rates, size at first maturity and body size are common in fishes (Alm, 1959; Iles, 1974). Such differences may reflect either environmental factors (i.e. temperature, food availability, population density and social organisation), or genetic differences or a combination of both environmental and genetic differences. Environmental effects on body size in fishes are well known, and evidence is accumulating that genetic effects also are important (Weatherley, 1972).

If there is a substantial genetic component in interpopulation differences in body size, it suggests that body size may be an important adaptive trait. However, in species with indeterminate growth and interpopulation variability in life-span, body size is not easy to quantify. Two simple measures of adult body size are: maximum size, and size at first maturity. Weatherley (op. cit.) indicates maturity in fishes is normally size specific. A number of theoretical reviews on life history strategies suggest age (size) at first maturity is a particularly sensitive life history variable (Cole, 1954; Meats, 1971; Schaffer, 1974). In this paper I use minimum size at first maturity as a measure of body size.

The threespine stickleback, Gasterosteus aculeatus, is widely distributed and exhibits striking interpopulation differences in body size (Moodie, 1972; Lindsey, 1975). Craig-Bennett (1931) and Baggerman (1957, 1972) both indicate the environmental factors triggering maturation (light and temperature) in Gasterosteus are effective only at sizes above a critical minimum body size. In addition, Baggerman (op. cit.) points out maturation in sticklebacks usually is attained only after a period of exposure to low temperatures and short day length. Presumably, this mechanism prevents 
individuals hatched in the early spring from spawning until the next spring, even though they may exceed the critical size for maturation within their first summer. Since breeding seasons are often protracted in Gasterosteus, there normally is considerable intrapopulation variability in size at first maturity.

Trivers (1972) argues that selective factors affecting life history variables often operate differently on males and females. This seems likely in Gasterosteus where males are territorial, build nests and defend the eggs and young, while females only enter breeding areas to spawn and take no part in parental care. Maturity in male sticklebacks is accompanied by changes in behaviour and colouration. Unfortunately, these changes are influenced by interactions with other males, so that the acquisition of a territory and nuptial colouration may not occur until well after physiological maturity is attained. This makes it difficult to determine male size at first maturity in many populations. In contrast, female size at first maturity is easily determined. A gravid female is unmistakable.

The present paper examines minimum size at first maturity in females from 25 southern Vancouver Island populations, and attempts to determine if the trait is inherited. Possible adaptive reasons for interpopulation differences in minimum size at first maturity are also examined.

\section{Material AND methods}

All sticklebacks used in this study are from lakes on southern Vancouver Island. None of the lakes are known to be open to anadromous sticklebacks, and the insular nature of lacustrine habitats makes it unlikely that immigration is common. The lakes cover a wide range of sizes, physiochemical and biological conditions (table 1).

Minimum female size at first reproduction was estimated by sampling during early breeding season (May and June). Confining samples to this period whon young-of-the-year are small reduces the probability of underestimating minimum size at first reproduction. Conceivably, samples taken later in the year could contain precocious females. Also, females produce several batches of eggs a season and some growth between batches is likely. Limiting samples to the early breeding season circumvents both problems.

Females are considered mature when gravid (i.e. separate, enlarged eggs in the ovaries). Size is measured as standard length (Hubbs and Lagler, 1958). All statistical analysis was performed on a PDP 11/45 computer using the U.B.C. Biology Data Centre's standard programs. The level of significance accepted in all statistical tests is $0 \cdot 05$.

Two estimates of minimum size at first reproduction were cxamined: the smallest gravid female in each population, and the mean of the 20 smallest females in each population. The two estimates are highly correlated $(r=0.96)$, but the variances of the estimates based on means are not homogeneous (Bartlett's test, $\mathrm{P}<0.0001$ ). Since the two estimates are correlated, and the lack of homogeneity for the mean estimates probably is due to year-class size overlap in some populations, the size of the smallest gravid female is used throughout this study as the estimator of minimum size at first maturity. Ideally, this estimate should be based on large samples of gravid females, but large samples are not available for many lakes. As 
a compromise between sample size and number of populations sampled, only collections containing 30 or more gravid females were analysed.

Samples from 25 lakes were large enough to be analysed, and individuals from 10 of these populations were brought into the laboratory for artificial rearing. These 10 populations represent a range of minimum sizes at first maturity (table 2), but do not include the populations with the largest and smallest body sizes. Eggs were stripped and fertilised from each population and then hatched and reared in aquaria housed in a controlled environment chamber. This chamber was maintained at $18^{\circ} \pm 1^{\circ} \mathrm{C}$ and a 12-hour day. Each population was reared in a series of 22-litre aquaria

TABle 1

List of lakes sampled on Vancouver Island arranged in ascending order of female size at first reproduction

\begin{tabular}{|c|c|c|c|c|}
\hline Lake & $\begin{array}{l}\text { Approx. surface } \\
\text { area (hectares) }\end{array}$ & $\begin{array}{l}\text { Total dissolved } \\
\text { solids (p.p.m.) }\end{array}$ & $\begin{array}{l}\text { Number of } \\
\text { fish species }\end{array}$ & $\begin{array}{l}\text { Minimum size } \\
\text { at first } \\
\text { reproduction (우) }\end{array}$ \\
\hline Lower Stella & $35 \cdot 6$ & 15 & 3 & $26 \cdot 1$ \\
\hline Kemp & $21 \cdot 3$ & 30 & 3 & $30 \cdot 6$ \\
\hline Harewood & 8.9 & 62 & 3 & $32 \cdot 1$ \\
\hline Nanaimo & $197 \cdot 6$ & 28 & 6 & $32 \cdot 9$ \\
\hline Horne & $850 \cdot 8$ & 44 & 6 & $34 \cdot 1$ \\
\hline Diver & $16 \cdot 9$ & 80 & 3 & $34.5(34.2-34.9)^{*}$ \\
\hline Brewster & $569 \cdot 6$ & 34 & 6 & $34 \cdot 5$ \\
\hline Sproat & $5458 \cdot 0$ & 36 & 6 & $34 \cdot 6$ \\
\hline Crystal & $5 \cdot 3$ & 22 & 2 & $34 \cdot 9$ \\
\hline Chemainus & $3 \cdot 5$ & 51 & 2 & $35 \cdot 0(34 \cdot 7-35 \cdot 8)^{*}$ \\
\hline Beck & $7 \cdot 1$ & 70 & 3 & $38 \cdot 0$ \\
\hline Campbell & $2278 \cdot 4$ & 56 & 6 & $38 \cdot 2$ \\
\hline Cowichan & $6721 \cdot 3$ & 55 & 7 & $38 \cdot 5$ \\
\hline Dougan's & $10 \cdot 6$ & 112 & 2 & $38 \cdot 9$ \\
\hline Blackjack & $3 \cdot 6$ & 50 & 2 & $39.2(38 \cdot 8-40 \cdot 6) *$ \\
\hline McCoy & $31 \cdot 1$ & 40 & 3 & $39 \cdot 5$ \\
\hline Mesachie & $65 \cdot 8$ & 45 & 6 & $39 \cdot 8$ \\
\hline Mohun & $683 \cdot 5$ & 37 & 6 & $40 \cdot 1$ \\
\hline Patterson & $12 \cdot 5$ & 42 & 3 & $40 \cdot 4$ \\
\hline Grey & $49 \cdot 8$ & 40 & 6 & $41 \cdot 5$ \\
\hline Holden & $35 \cdot 6$ & 101 & 5 & $42 \cdot 5$ \\
\hline Mud & $2 \cdot 7$ & 26 & 2 & $44 \cdot 3$ \\
\hline Brannen & $112 \cdot 1$ & 49 & 6 & $45 \cdot 8(45 \cdot 4-46 \cdot 3) *$ \\
\hline Michael & $35 \cdot 6$ & 88 & 4 & $51 \cdot 8$ \\
\hline Great Central & $5354 \cdot 2$ & 30 & 7 & $52 \cdot 7$ \\
\hline
\end{tabular}

containing 10 individuals per aquarium. Newly hatched young were fed live Artemia nauplii and later frozen adult Artemia. Feeding was ad libitum. When the largest fish were approximately $25 \mathrm{~mm}$ long, the environmental temperature was gradually reduced to $6^{\circ} \mathrm{C}$ and light duration to 6 hours. This regime was maintained for 2 months and then returned to $18^{\circ} \mathrm{G}$ and a 12-hour day by a series of steps over the period of a month.

Size at first reproduction (first egg batch) was recorded for all females. The smallest female to reach maturity in each population gave a laboratory estimate of minimum size at first reproduction. These laboratory estimates were compared to estimates for the original wild populations by regression analysis. The regression coefficient was used as an indicator of the degree of genetic control over the trait. 
TABLE 2

Laboratory and field estimates of minimum female size at first reproduction for 10 populations

\begin{tabular}{lcr}
\multicolumn{1}{c}{ Lake } & $\begin{array}{c}\text { Estimated minimum size } \\
\text { at first reproduction } \\
\text { (based on field collections) }\end{array}$ & $\begin{array}{r}\text { Estimated min } \\
\text { at first reprod } \\
\text { (laborator }\end{array}$ \\
Harewood & $32 \cdot 1$ & $35 \cdot 2$ \\
Diver & $34 \cdot 5^{*}$ & $35 \cdot 4$ \\
Sproat & $34 \cdot 6$ & $39 \cdot 2$ \\
Chemainus & $35 \cdot 0^{*}$ & $40 \cdot 2$ \\
Crystal & $34 \cdot 9$ & $38 \cdot 0$ \\
Beck & $38 \cdot 0$ & $40 \cdot 8$ \\
Dougan's & $38 \cdot 9$ & $39 \cdot 2$ \\
Blackjack & $39 \cdot 2^{*}$ & $42 \cdot 7$ \\
Mohun & $40 \cdot 1$ & $42 \cdot 3$ \\
Brannen & $45 \cdot 8^{*}$ & $48 \cdot 4$
\end{tabular}

* Mean of four years.

$r=0.92$.

$y=6 \cdot 40+0 \cdot 90 x$, wild estimate as independent variable.

Multiple regression analysis was used to explore possible relationships between minimum size at first reproduction and a series of potentially important ecological variables. Fisheries biologists sometimes combine lake morphometry and total dissolved solids (TDS) in an index of productivity. Within a circumscribed geographic area this so-called "Morphoedaphic Index" is often a reliable and robust estimator of fish yield (see Ryder et al., 1974, for a review). I use the morphoedaphic index to indicate the potential food resources in the different lakes. In the same vein, the number of cohabiting fish species is used as an index of interspecific competition.

Trout predation was measured by sampling trout with gill-nets (25-100 mm mesh) during the same time period sticklebacks were sampled (May and June). Ten of the 25 lakes were sampled for trout and the results are listed in table 3 . Predation intensity was estimated by the percentage of large trout $(>200 \mathrm{~mm}$ standard length) containing sticklebacks. The

\section{TABLF, 3}

Trout numbers and estimated predation intensity (springtime) from gill-net samples for 10 lakes (equal sampling effort in all lakes)

\begin{tabular}{lcccc}
\multicolumn{1}{c}{ Lake } & $\begin{array}{c}\text { Total number } \\
\text { of trout }\end{array}$ & $\begin{array}{c}\text { Number of } \\
\text { trout }>200 \mathrm{~mm}\end{array}$ & $\begin{array}{c}\text { Percentage of trout } \\
>200 \mathrm{~mm} \text { containing } \\
\text { sticklebacks }\end{array}$ \\
Harewood & 57 & 26 & $4 \%(1)^{*}$ \\
Diver & 24 & 22 & $59 \%(13)$ \\
Chemainus & 26 & 13 & $7 \%(1)$ \\
Beck & 76 & 39 & $2 \%$ & $(1)$ \\
Dougan's & 54 & 23 & $8 \%$ & $(2)$ \\
Blackjack & 21 & 10 & $20 \%(2)$ \\
Mesachie & 23 & 18 & $16 \%(3)$ \\
Holden & 22 & 14 & $14 \%(2)$ \\
Brannen & 49 & 23 & $43 \%(10)$ \\
Michael & 27 & 21 & $14 \%(3)$
\end{tabular}

* Numbers in brackets are actual number of large trout containing stickleback remains. 
reason for using trout over $200 \mathrm{~mm}$ long is that independent data indicate trout less than $200 \mathrm{~mm}$ only rarely eat sticklebacks.

\section{Results}

\section{(i) Laboratory reared populations}

Table 2 lists the minimum and average sizes at first maturity for 10 laboratory reared populations along with the estimated minimum size at first maturity for their wild progenitors. Since all populations were reared simultaneously in the same controlled environment chamber, the differences between populations are probably genetic. The laboratory estimates of minimum size were then regressed against the estimates obtained from the wild populations. The regression coefficient of 0.90 is interpreted as evidence for a considerable inherited component in minimum size at first maturity in female Gasterosteus.

\section{(ii) Wild populations}

Table 1 lists the estimated minimum size at first maturity for females from 25 southern Vancouver Island populations. The populations are arranged in ascending size order. The minimum sizes at first maturity range from $26 \cdot 1 \mathrm{~mm}$ to $52.7 \mathrm{~mm}$ and form a continuum, but 19 of the 25 populations are clustered in the $34-44 \mathrm{~mm}$ size range. The laboratory rearing data (table 2) and differences in estimates between years in four populations (table 1) suggest differences of 5 or $6 \mathrm{~mm}$ in estimates based on wild populations are within the range of sampling error. However, the rearing experiments also indicate that even in the populations clustered in the $34-44 \mathrm{~mm}$ size range there are detectable inherited differences in minimum size at first reproduction. This suggests that, in spite of sampling error, populations at the small and large ends of the size continuum probably represent biologically real differences in minimum size at first reproduction.

\section{(iii) Multiple regression analysis}

All regression coefficients resulting from the multiple regression analysis are non-significant. This does not mean that food resources and interspecific competition have no effects on minimum size at first reproduction, but if such effects exist my analysis did not detect them.

\section{(iv) Predation}

Table 3 lists diet analyses on trout collected from 10 study lakes. In eight lakes trout predation was low (2-16 per cent) at the time of collection, but in two lakes predation is high (43-59 per cent) and apparently comparable to the level (40-55 per cent) recorded by Moodie (1972) for Mayer Lake on the Queen Charlotte Islands. Since Hagen and Gilbertson (1972) noted seasonal shifts in rainbow trout predation on sticklebacks, my comparison is confined to Moodie's spring samples. Such seasonal diet shifts probably occur in cut-throat trout on Vancouver Island. As a result, predation may be higher in all lakes during winter. However, since all my samples were taken at the same time, the differences between the two high-predation lakes and the other lakes are interpreted as real. Why trout prey extensively on sticklebacks in some lakes, and only occasionally 
in others, is unknown. However, cursory examination of Vancouver Island lakes suggests cover, particularly vegetation, and alternate prey may be important factors.

\section{Discussion}

The results of the laboratory rearing experiment clearly demonstrate a significant genetic component in interpopulation differences in minimum size at first reproduction. Since Vancouver Island was ice-covered until about 13,000 B.P. (Mathews et al., 1970), all populations are of geologically recent origin. This, combined with populations with strikingly different sizes at first reproduction in adjacent, connected lakes, suggests that minimum size at first maturity is an adaptive trait that evolves in situ.

A number of theoretical models explore conditions under which selection might alter size (age) at first reproduction. Cole (1954) and Lewontin (1965) suggest that in expanding populations selection tends to push size at first reproduction towards the physiological minimum. Since most of my lakes are relatively undisturbed and of similar age, it is unlikely that any of the populations are expanding.

In contrast, Gadgil and Bossert (1970) suggest delaying first reproduction beyond the physiological minimum size can be advantageous. Egg number in Gasterosteus increases with size (Wooten, 1972), and there is evidence that in some situations large body size provides a refuge from predation (Moodie, 1972). This combination approximates the conditions Schaffer (1974) suggests lead to selection for delayed maturity.

The specific environmental factors selecting for different sizes at first rcproduction in the various lakes are unknown. The absence of significant regression coefficients in the multiple regression analysis suggests that no simple relationships exist. However, using morphometric and edaphic data to index productivity, and number of cohabiting fish species to index interspecific competition, is at best crude. More careful analysis may reveal effects of productivity and interspecific competition on minimum size at first maturity.

Predation intensity is not included in the multiple regression analysis because no satisfactory measure of predation intensity is available for all 25 lakes. Yet, predation seems likely to be involved in selection for different sizes at first reproduction, particularly in Gasterosteus where body size, along with spine length, is an important variable affecting manipulation time and capture success for a common predator, the cut-throat trout (Salmo clarki).

The major predators on adult sticklebacks are probably birds and predaceous fish. Invertebrate predation may be important on juveniles. The two common predaceous fish on Vancouver Island are cut-throat trout and prickly sculpins (Cottus asper). Only cut-throat trout are present in all 25 lakes, and it is only for this species that comparative predation data exist. In two lakes (Brannen and Diver) the intensity of trout predation is comparable to that Moodie (op. cit.) records for Mayer Lake. Mayer Lake sticklebacks have the largest minimum size at first reproduction (69 $\mathrm{mm}$ ) of any known population, and Moodie suggests large size is at least in part an adaptation to predation. Brannen Lake sticklebacks are not as large as Mayer Lake sticklebacks, but with a minimum size at first maturity 
of $45.4 \mathrm{~mm}$ they are larger than most populations. In contrast, Diver Lake sticklebacks have a smaller $(34.5 \mathrm{~mm})$ size at first maturity than most populations. Apparently, intense trout predation does not invariably select for a large minimum size at first reproduction.

Brannen and Diver lakes not only share similar levels of predation but also they are adjacent and connected. The striking difference in size at first maturity between the lakes suggests that perhaps high levels of trout predation can select for either large or small minimum size at first maturity. The size range of predators may be crucial. Where large predators are rare there is potentially a size refuge from predation and selection may favour delaying maturity until after a relatively safe size is reached. In contrast, where large predators are common a size refuge may be unattainable and then the optimal reproductive strategy is to breed as close to the physiological minimum size as other constraints allow.

This hypothesis predicts lakes with levels of trout predation comparable to Brannen, Diver and Mayer lakes should contain either large or small sticklebacks, and that large sticklebacks will be associated with small trout and small sticklebacks with large trout. Although not a test of this hypothesis, Diver Lake trout are significantly larger than Brannen Lake trout (214v. $271 \mathrm{~mm}, \mathrm{P}<0.05$, Scheffe's Test). Similar, independently derived, data could test the hypothesis.

The above hypothesis applies to populations exposed to high levels of trout predation. Factors selecting for different sizes at first reproduction in populations where predators are absent, or the level of predation is low, remain unknown.

\section{REFERENCES}

ALM, G. 1959. Connection between maturity, size and age in fishes. Inst. Freshw. Res., Drottningholm, Rept. 40, 5-145.

BAGGERMAN, B. 1957. An experimental study on the timing of breeding and migration in the three-spined stickleback (Gasterosteus aculeatus L.). Arch. Néerl. de Zoologie, XII, 105-318.

BagGerman, B. 1972. Photoperiodic responses in the stickleback and their control by a daily rhythm of photosensitivity. Gen. Comp. Endoc., Suppl. 3, 466-476.

COLE, L. C. 1954. The population consequences of life history phenomena. Quart. Rev. Biol., 29, 103-137.

CRAIG-BENNETT, A. 1931. The reproductive cycle of the three-spined stickleback, Gasterosteus aculeatus L., Phil. Trans. Roy. Soc. Lond., B, 219, 197-279.

GADGIL, M. D., AND BOSSERT, W. H. 1970. Life history consequences of natural selection. Am. Nat., 104, 1-24.

HAGEN, D. W., AND GILBERTSON, L. G. 1972. Geographic variation and environmental selection in Gasterosteus aculeatus L. in the Pacific Northwest, America. Evolution, 26, $32-51$.

HUBBs, C. L., AND LAGLeR, K. F. 1958. Fishes of the Great Lakes. Cranbrook Inst. Sci., Bull. 26, $213 \mathrm{pp}$.

ILES, T. D. 1974. The tactics and strategy of growth in fishes. In Sea Fisheries Research, ed. F. R. Harden Jones, pp. 331-345. Elek Science, London.

1.EWONTIN, R. C. 1965. Selection for colonizing ability. In The Genetics of Colonizing Species, ed. H. G. Baker and G. L. Stebbins, pp. 79-94. Academic Press, New York.

LINDSEY, C. C. 1975. Pleomerism, the widespread tendency among related fish species for vertebral number to be correlated with maximum body length. F. Fish. Res. Bd. Canada, 32, 2453-2469.

MATHEWS, W. H., FYles, J. G., AND NASMith, H. W. 1970. Postglacial crustal movements in southwestern British Columbia and adjacent Washington State. Can. F. Earth Sci., 7, 690-702. 
MAYR, E. 1963. Animal Species and Evolution, 797 pp. Belknap Press, Harvard.

MEATS, A. 1971. The relative importance to population increase of fluctuations in mortality, fecundity, and the time variables of the reproductive schedule. Oecologia, 6, 233-237.

MOODIE, G. E. E. 1972. Prcdation, natural selection and adaptation in an unusual threespine stickleback. Heredity, 28, 155-167.

RYDER, R. A., KERR, S. R., LOFTUS, K. H., AND REgIER, H. A. 1974. The morphoedaphic index, a fish yield estimator-review and evaluation. 7. Fish. Res. Bd. Canada, 31, 663-688. Schaffer, w. M. 1974. Selection for optimal life histories: the effects of age structure. Ecology, 55, 291-303.

Trivers, R. L. 1972. Parental investment and sexual selection. In Sexual Selection and the Descent of Man, 1871-1971, ed. B. Campbell, pp. 136-179. Aldine-Atherton, Chicago. weatherley, A. w. 1972. Growth and Ecology of Fish Populations, 293 pp. Academic Press, London.

wooten, R. J. 1972. The effect of size of food ration on egg production in the female three-spine stickleback, Gasterosteus aculeatus L., .7. Fish. Biol. 4 89-96 